\title{
Splicer Device
}

National Cancer Institute

\section{Source}

National Cancer Institute. Splicer Device. NCI Thesaurus. Code C50185.

A device designed to join pieces of a material into a continuous length. 